\title{
A multi-centre case series of alectinib-related erythrocyte membrane changes and associated haemolysis
}

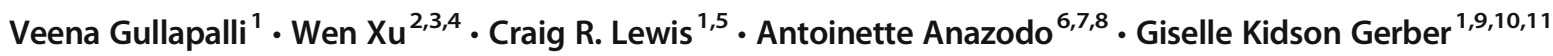

Received: 2 September 2020 / Accepted: 12 November 2020 / Published online: 7 January 2021

(C) The Author(s) 2021

\begin{abstract}
Alectinib is an orally bioavailable anaplastic lymphoma kinase (ALK) inhibitor indicated for ALK mutated non-small cell lung cancer (NSCLC). This case series documents the development of significant erythrocyte membrane changes associated with alectinib use in six patients. Morphological findings found on blood film examination include moderate-marked acanthocytes, spheroacanthocytes, and one case demonstrated moderate schistocytes. Two patients in this multi-centre case series developed grade 1 anaemia, and four patients developed grade 2 anaemia. Two patients suffered significant non-immune-related haemolysis. One patient had a co-existing $\beta$ thalassaemia trait and required treatment cessation due to severe haemolysis. Low-grade anaemia was seen in $22 \%$ of patients using alectinib in the ALEX trial and 5\% developed $\geq$ grade 3 anaemia. Alterations in erythrocyte morphology and membrane structure have not been reported in the safety data and clinical trials to date. Drug-induced acanthocytosis is a rare phenomenon and has previously been reported with high-dose prostaglandin administration only. This case series highlights this important laboratory finding with alectinib use and associated clinical sequelae. Alectinib-associated acanthocytosis is likely to be more prevalent than previously recognised. We also highlight the need for vigilance in haematopathology departments for unexpected laboratory findings associated with novel therapies. These findings can be detected in the post-marketing surveillance phase and may have serious clinical implications for patients.
\end{abstract}

Keywords Alectinib $\cdot$ Acanthocytes $\cdot$ Erythrocyte membrane $\cdot$ Haemolysis $\cdot$ Anaplastic lymphoma kinase inhibitor

\section{Introduction}

We have observed significant changes in erythrocyte morphology on peripheral blood film examination of six patients treated with alectinib. Clinical sequelae ranged from asymptomatic anaemia to severe haemolysis.

Alectinib is an orally bioavailable anaplastic lymphoma kinase (ALK) tyrosine kinase inhibitor indicated for non-

Veena Gullapalli

veena.gullapalli@gmail.com

1 Prince of Wales Clinical School, University of New South Wales, Sydney, NSW, Australia

2 Princess Alexandra Hospital, Brisbane, Australia

3 The University of Queensland, Brisbane, Australia

4 Queensland University of Technology, Brisbane, Australia

5 Department of Medical Oncology, Prince of Wales Hospital, Sydney, Australia small cell lung cancer (NSCLC) demonstrating the EML4$A L K$ gene rearrangement [1]. It has also been used in malignancies which demonstrate ALK fusion protein expression including anaplastic large cell lymphoma, neuroblastoma, and inflammatory myofibroblastic tumour [2]. Although in vivo animal studies during the pre-clinical phase reported mild haemolysis [3], to the authors' knowledge, there are no reports of altered erythrocyte morphology in published trial

6 School of Women's and Children's, University of New South Wales, Sydney, Australia

7 Nelune Comprehensive Cancer Centre, Prince of Wales Hospital, Randwick, Sydney, Australia

8 Kids Cancer Centre, Sydney Children's Hospital, Randwick, Sydney, Australia

9 Department of Haematology, New South Wales Health Pathology, Randwick, Sydney, NSW, Australia

10 Department of Haematology, Prince of Wales Hospital, Randwick, Sydney, Australia

11 University of New South Wales, NSW Kensington, Australia 
data. In this multi-centre case series, we report six cases with new onset significant acanthocytosis and spheroacanthocytosis on peripheral blood film examination.

\section{Cases reports}

The index case was a 79-year-old female who presented with a malignant pleural effusion secondary to metastatic ALK-positive NSCLC. She commenced ceritinib, however gastrointestinal toxicity and hepatic transaminitis resulted in treatment change to alectinib. Three months after commencement of alectinib, she was admitted to hospital for recurrence of the malignant pleural effusion. There was a new normocytic normochromic anaemia with haemoglobin $100 \mathrm{~g} / \mathrm{L}$ and MCV $88 \mathrm{fL}$. The blood film demonstrated acanthocytes, spherocytes, left shift with neutrophilia, and hypereosinophilia (Fig. 1a). Renal function, liver function tests, and electrolyte profile were within normal limits. Lipid profile or thyroid function tests were not available. The patient subsequently died from progressive lung cancer.

Patient 2 was a 66-year-old male incidentally found to have moderate acanthocytes and mild spherocytes on a blood film examination (Fig. 1b) following commencement of alectinib for relapsed ALK-positive lung adenocarcinoma in mid-2017. Haematological indices prior to initiation of alectinib were within normal parameters. Blood film prior to initiating therapy was unavailable. During therapy with alectinib, the patient developed hypothyroidism and was started on thyroxine $100 \mathrm{mcg}$ daily. Haematological indices performed at the time of the blood film demonstrated a normocytic anaemia with haemoglobin of $107 \mathrm{~g} / \mathrm{L}, \mathrm{MCV} 87 \mathrm{fL}$, and RDW $42 \mathrm{fL}$. Lactate dehydrogenase (LDH) level was mildly elevated at $266 \mathrm{U} / \mathrm{L}(150-250 \mathrm{U} / \mathrm{L})$, and haptoglobin was $0.8 \mathrm{~g} / \mathrm{L}(0.3-$ $2.0 \mathrm{~g} / \mathrm{L}$ ). The patient's renal function, liver function tests, electrolyte profile, and lipid profile were normal.

Patient 3 is a 14-year-old female who was diagnosed with metastatic ALK-positive lung adenocarcinoma and commenced treatment with alectinib. She was also taking trimethoprim-sulfamethoxazole for Pneumocystis jirovecii prophylaxis. Prior to initiation of alectinib, haemoglobin was $107 \mathrm{~g} / \mathrm{L}, \mathrm{MCV} 71 \mathrm{fL}$, platelet count $394 \times 10^{9} / \mathrm{L}$, and $\mathrm{WCC}$ $7 \times 10^{9} / \mathrm{L}$. Iron studies demonstrated a mild iron deficiency with ferritin $49 \mu / \mathrm{L}$ and transferrin saturation of $4 \%$. A haemoglobin electrophoretogram was normal. Blood tests undertaken two months after initiating alectinib demonstrated a persistent mild microcytic anaemia with haemoglobin of $96 \mathrm{~g} /$ $\mathrm{L}$ and MCV $71 \mathrm{fL}$. The blood film (Fig. 1c) showed marked microcytosis and moderate acanthocytes. Thyroid function tests were unremarkable. The patient remains in remission from the lung adenocarcinoma.

Patient 4 is a 30 -year-old female who was diagnosed with a retroperitoneal primary neuroblastoma at age 19 . Prior treatments included chemotherapy, surgery, radiotherapy, and cis-retinoic acid. Recurrence four years later was treated with surgery and radiotherapy. Following a further recurrence, molecular analysis identified ALK fusion protein and the patient commenced alectinib. The initial blood film demonstrated a mild normocytic normochromic anaemia with normal red cell morphology
Fig. 1 a Peripheral blood film (PBF) from blood tests three months after initiation of alectinib in patient 1 . It demonstrates a normocytic anaemia with severe acanthocytosis, left shift with neutrophilia, and hypereosinophilia, $\times 100$ Wright Geimsa. b PBF of patient 2 24 months after starting alectinib demonstrating moderate to severe acanthocytosis, $\times 100$ Wright Geimsa. c PBF of patient 3 two months of alectinib treatment demonstrating a microcytic hypochromic anaemia and moderate acanthocytosis, $\times 100$ Wright Geimsa. d PBF of patient 6 three months after alectinib was initiated demonstrating severe acanthocytosis and spheracanthocytes with reticulocytosis, $\times 100$ Wright Geimsa

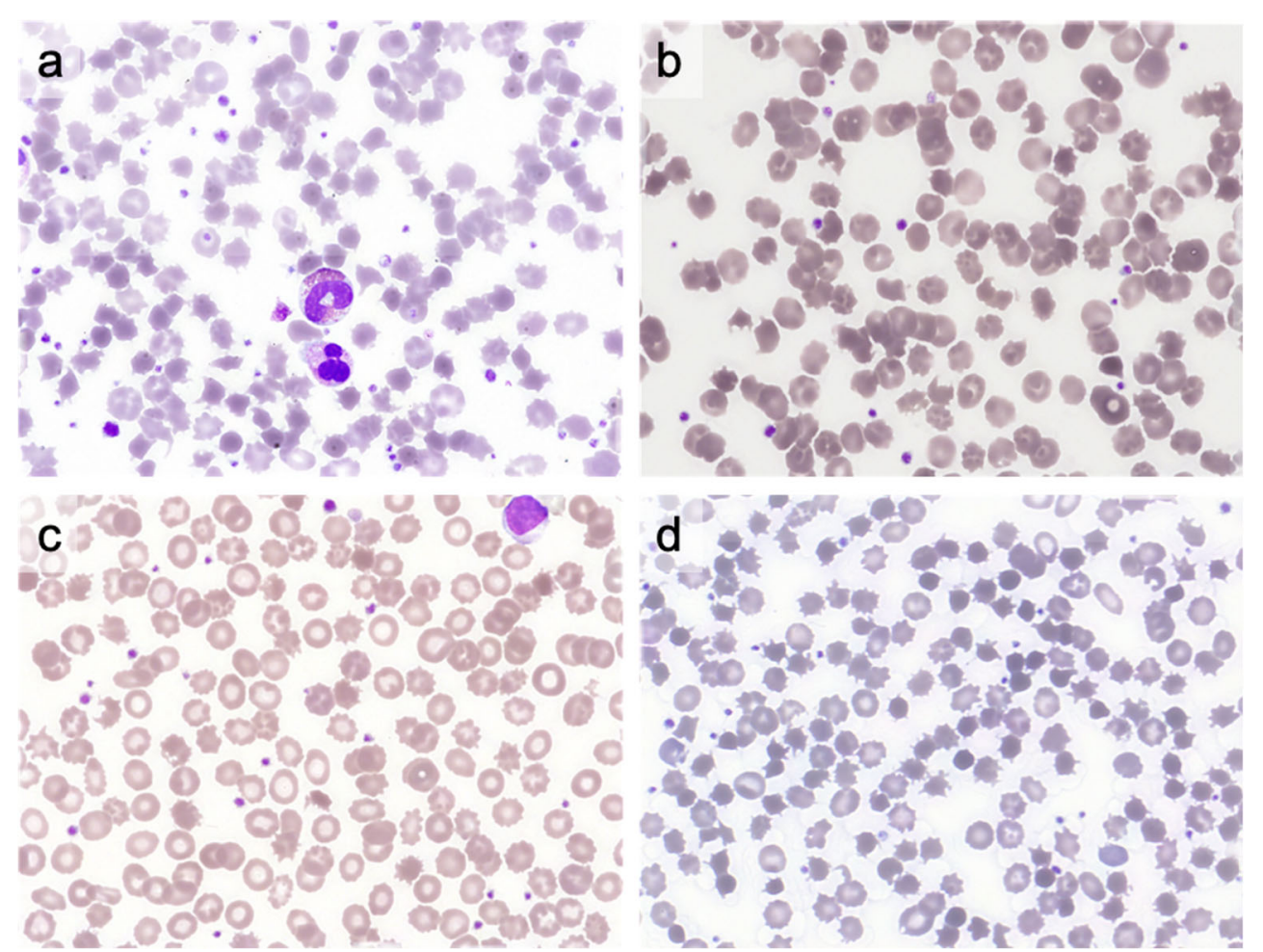


(Fig. 2a). Blood films generated on D14, D50, and D127 of therapy (Fig. $2 b$ \& 2c) demonstrated increasing numbers of acanthocytes and there was a mild improvement in haemoglobin (Table 1). Renal function, liver function, electrolyte profile, thyroid function, and lipid profile remained within normal limits.

Patient 5 is a 66-year-old male treated for stage II NSCLC in 2014 with a lobectomy, followed by adjuvant chemotherapy with cisplatin and vinorelbine. Past medical history included localised prostate cancer which remains under surveillance and known $\beta$ thalassaemia trait. In 2015 , he developed multiple cerebral metastases and received whole brain radiotherapy. In 2020, he developed recurrent brain metastases. Presence of an ALK fusion gene was confirmed and alectinib was commenced. Baseline haemoglobin was $115 \mathrm{~g} / \mathrm{L}$, with an $\mathrm{MCV}$ of $62 \mathrm{fL}$ and the film demonstrated microcytosis and basophilic stippling, consistent with known $\beta$ thalassaemia trait (Fig. 2d). After a month on alectinib, he developed symptomatic anaemia with haemoglobin of $81 \mathrm{~g} / \mathrm{L}$. Haemolysis was confirmed with an unconjugated hyperbilirubinaemia to $31 \mu \mathrm{mol} / \mathrm{L}$, elevated reticulocyte count of $137 \times 10^{9} / \mathrm{L}$, elevated LDH of $836 \mathrm{U} / \mathrm{L}$, and low haptoglobin of $0.04 \mathrm{~g} / \mathrm{L}$. The direct antiglobulin test (DAT) was negative. Concurrent with this, there was a new grade 3 AST and ALT derangement (Table 1). His platelet count remained in the normal range and an ADAMTS13 level was normal at $0.67 \mathrm{IU} / \mathrm{mL}$ (RR 0.40 to $1.30 \mathrm{IU} / \mathrm{mL}$ ). The blood film demonstrated marked acanthocytosis, fragmentation, microspherocytes, and polychromasia. Alectinib was ceased with a plan to rechallenge with an alternative ALK inhibitor upon disease progression, which has not yet occurred. Post-alectinib cessation, follow-up blood films demonstrated persistent morphological changes, but normalisation of haemolytic parameters, with recovery of haemoglobin to $100 \mathrm{~g} / \mathrm{L}$ by 6 weeks (see Table 1 ).

Patient 6 is a 77-year-old female diagnosed with ALKpositive NSCLC with nodal and pleural metastases. Comorbidities included obstructive airways disease and hypothyroidism for which she was taking thyroxine $50 \mathrm{mcg}$ daily. Three months post-initiation of alectinib $600 \mathrm{mg}$ BD, her haemoglobin had decreased from a baseline of $133 \mathrm{~g} / \mathrm{L}$ to $104 \mathrm{~g} / \mathrm{L}$ with evidence of DAT-negative haemolysis (Table 1). The blood film showed marked spheroacanthocytes, with minimal red cell fragmentation (Fig. 1d). Alectinib was withheld with improvement of anaemia and normalisation of haemolysis markers after two weeks. She was rechallenged at the modified dose of alectinib at $450 \mathrm{mg} \mathrm{BD}$, but after 12 weeks, there was recurrence of haemolysis with hyperbilirubinaemia to $49 \mu \mathrm{mol} / \mathrm{L}$, reticulocyte count of $124 \times 10^{9}$, and a decreased haptoglobin to $0.02 \mathrm{~g} / \mathrm{L}$. Alectinib was ceased permanently, and brigatinib, an alternative ALK inhibitor, commenced. Four weeks after cessation of alectinib and initiation of brigatinib, haematological indices indicated complete resolution of haemolysis, confirming this was likely an alectinibspecific effect.

\section{Discussion}

We have reported six cases of significant alterations in erythrocyte morphology secondary to alectinib. Case 4 demonstrated this transformation of normal erythrocytes to those with spiculated membranes after initiation of alectinib. Patients predominantly demonstrated mild anaemia, however two patients developed significant DAT-negative haemolysis and one demonstrated severe erythrocyte fragmentation. In these cases, there was significant improvement in haemolytic markers after alectinib cessation. Significant haemolysis recurred after re-initiation of alectinib at a reduced dose in case 6. This indicates a possible effect of alectinib on the metabolism and membrane integrity of erythrocytes. These changes can be seen soon after initiating therapy. It remains unclear whether this is a dose-dependent effect.

Low-grade anaemia is a common toxicity seen with alectinib and was reported in 14-22\% of patients in studies $[1,4]$. Although the majority of alectinib-induced anaemia is grade 1 or 2 severity, clinical trials report that $1-5 \%$ of the patients experience grade 3 or worse anaemia $[1,4,5]$. The recent safety and efficacy update from phase 3 ALEX trial demonstrated that $\geq$ grade 3 anaemia was more frequent with alectinib when compared to crizotinib [3]. Mild increases in bilirubin are also commonly observed with alectinib, with an overall incidence of $15 \%$ in the ALEX trial [1] and 2\% experiencing $\geq$ grade 3 bilirubinaemia. This raises the suspicion of underlying haemolysis. Although animal studies have shown evidence of alectinib-induced abnormal red cell morphology and increase in reticulocytosis [3], to our knowledge, blood films or haemolytic parameters were not routinely monitored in the clinical trials.

Acanthocytes refers to contracted erythrocytes exhibiting multiple membrane projections which contrast with the recognisable discoid structure. This is seen in conditions which alter the ratio sphingomyelin and glycerophospholipids [6] or alter the anchorage of the cytoskeleton network to the erythrocyte membrane [7]. It is more commonly seen in advanced cirrhosis, malnutrition, hypothyroidism, and inherited disorders such as neuroacanthocytosis and hypobetalipoproteinaemia [8]. Drug-induced acanthocytosis is a rare phenomenon. The only reported case was with high-dose prostaglandin, which was also associated with significant haemolysis [9]. ALK tyrosine kinase activates multiple pathways associated with cell proliferation and differentiation, but the mechanism of alectinibinduced membrane changes remains unknown. The haemolysis seen in acanthocytosis syndromes is hypothesised to be secondary to reduced erythrocyte deformability leading to splenic entrapment and macrophage phagocytosis [10]. However, the numerous fragments in case 5 suggested a component of intravascular haemolysis. We hypothesise that the significant haemolysis seen in this specific case may be due to concurrent haemoglobinopathy further impairing erythrocyte 


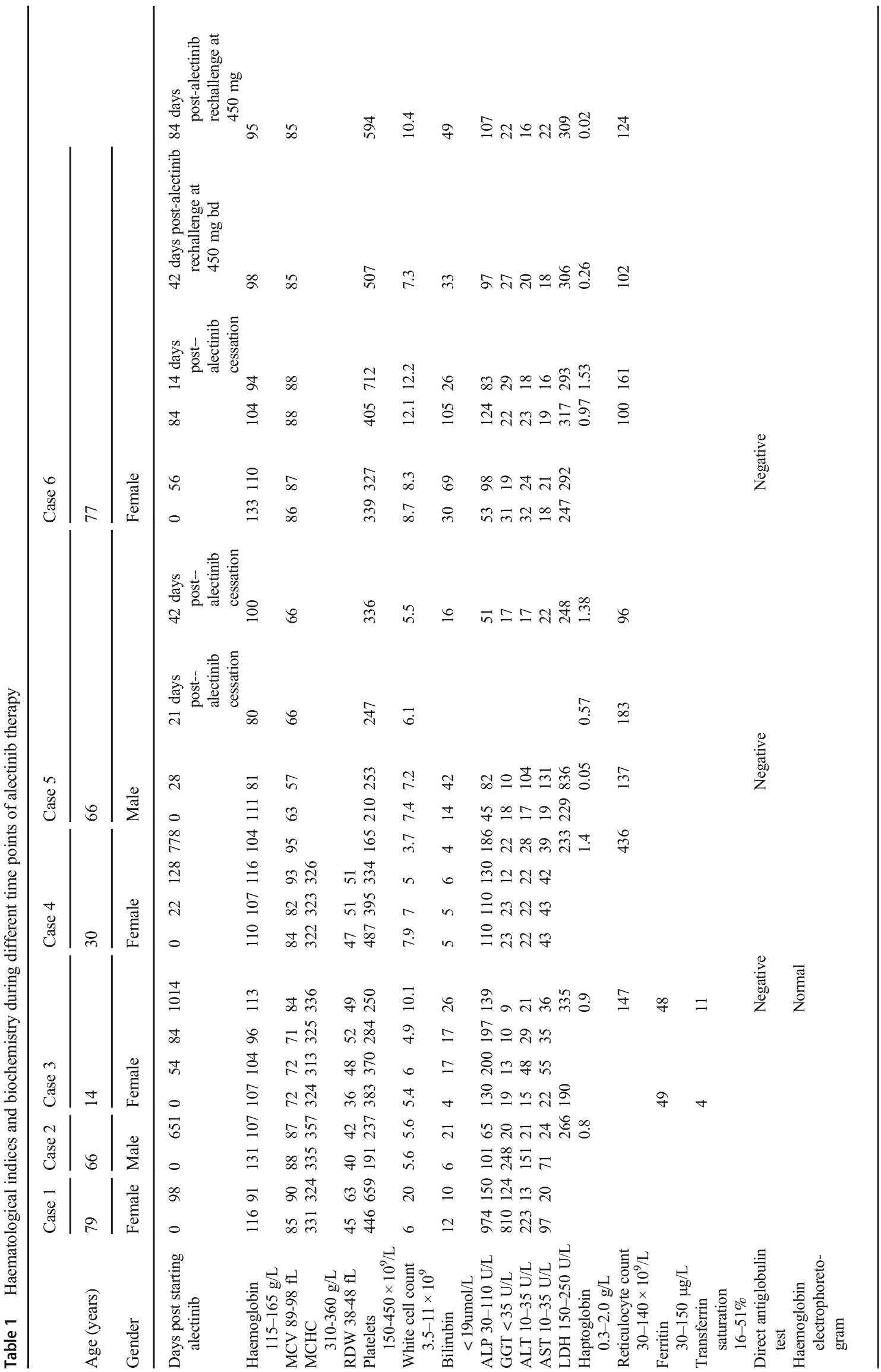



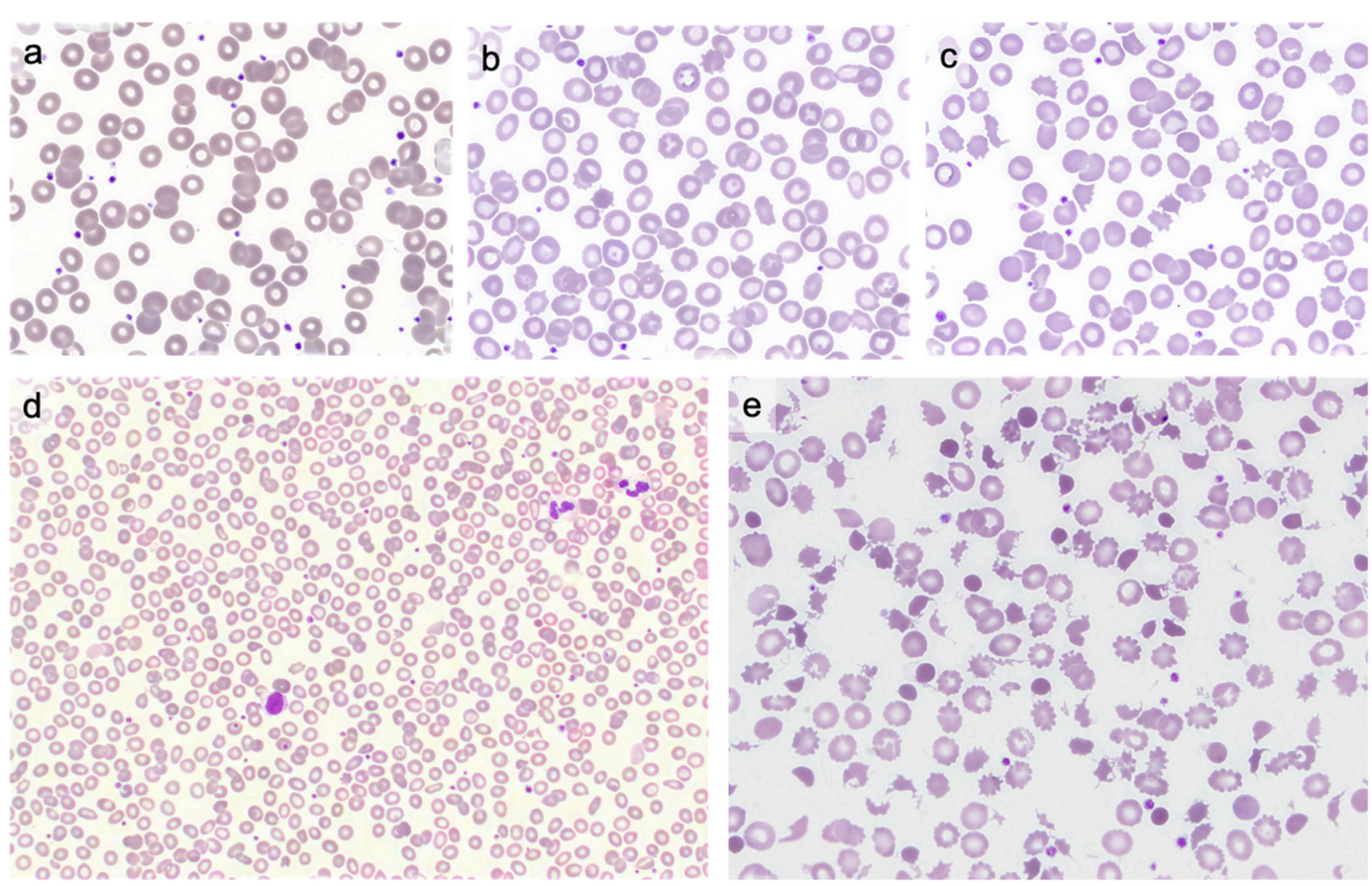

Fig. 2 a PBF of patient four prior to initiating alectinib demonstrating normocytic normochromic cells, $\times 100$ Wright Geimsa b PBF day 50 post-alectinib demonstrating occasional acanthocytes in patient $4, \times 100$ Wright Geimsa. c PBF day 127 post-alectinib demonstrating moderate acanthocytes in patient $4, \times 100$ Wright Geimsa. d PBF of patient 5 prior to the initiation of alectinib which demonstrates microcytic anaemia, basophilic stippling, mild anisopoikilocytosis. and occasional target cell

deformability needed to pass through the microvasculature of the spleen [11].

To our knowledge, the described red cell changes are unique to alectinib rather than a class effect. We are not aware of acanthocytosis or haemolysis associated with other ALK inhibitors including crizotinib, ceritinib, brigatinib, or lorlatinib. This was confirmed in case 6 , whereby the haemolytic changes resolved after four weeks of ceasing alectinib, despite starting brigatinib. We propose that in the situation where clinically significant haemolysis attributable to alectinib occurs, an alternative ALK inhibitor should be considered. In cases of asymptomatic patients with only morphological changes on blood film, it may be reasonable to continue alectinib with close observation of haematological indices and haemolytic parameters. We would also recommend increased vigilance when using this medication in patients with known haemoglobinopathies.

This report highlights the need for both clinicians and laboratory haematologists to be observant for unrecognised offtarget effects of novel agents. We recommend routine blood consistent with $\beta$ thalassemia trait, $\times 40$ Wright Geimsa e PBF after one month of therapy for patient 5 showing marked fragmentation and marked anisopoikilocytosis, with irregularly contracted cells, acanthocytes, microspherocytes, and polychromasia. There is background microcytosis and basophilic stippling, consistent with known $\beta$ thalassaemia trait, $\times 100$ Wright Geimsa

film examinations and regular haemolytic markers to be undertaken in patients receiving alectinib.

Acknowledgements The authors would like to thank Yin Yuan, Mary Hester, Unni Krishnan Leela S Nair for assisting with collection, storage, and images of the blood films.

Author contributions Veena Gullapalli-authorship of manuscript, editing of all versions of the manuscript, image acquisition, table construction

Wen $\mathrm{Xu}$-authorship of manuscript, editing of all versions of the manuscript, acquisition of data, confirmed data integrity

Craig R Lewis - authorship of manuscript, editing of all versions of the manuscript, acquisition of date, confirmed data integrity

Antoinette Anozodo - authorship of manuscript, editing of all versions of the manuscript, acquisition of date, confirmed data integrity

Giselle Kidson Gerber - authorship of manuscript, editing of all versions of the manuscript, acquisition of date, confirmed data integrity, analysis of data.

\section{Compliance with ethical standards}

Conflict of interest Author Wen $\mathrm{Xu}$ sits on the advisory board for Novartis, Merck Serono. Author Wen Xu has received speakers fees from 
Merck Serono, MSD, educational support from AZD, Roche, and research funding from Merck Serono. Author Craig R Lewis has a financial disclosure of having been on the Astra Zeneca Advisory Board. Authors Veena Gullapalli, Giselle Kidson Gerber, and Antoinette Anazodo declare that they have no conflict of interests.

Consent to publish The authors affirm that human research participants consented to use of their data and publication of their data in a journal. Informed written consent for publishing their data and photographs was obtained.

Ethics approval This retrospective case series was approved on July 8 , 2020, by the South Eastern Local Health District Human Research Ethics Committee and was deemed to meet the requirements of the National Statement on Ethical Conduct in Human Research.

Open Access This article is licensed under a Creative Commons Attribution 4.0 International License, which permits use, sharing, adaptation, distribution and reproduction in any medium or format, as long as you give appropriate credit to the original author(s) and the source, provide a link to the Creative Commons licence, and indicate if changes were made. The images or other third party material in this article are included in the article's Creative Commons licence, unless indicated otherwise in a credit line to the material. If material is not included in the article's Creative Commons licence and your intended use is not permitted by statutory regulation or exceeds the permitted use, you will need to obtain permission directly from the copyright holder. To view a copy of this licence, visit http://creativecommons.org/licenses/by/4.0/.

\section{References}

1. Peters S, Camidge DR, Shaw AT, Gadgeel S, Ahn JS, Kim DW, Ou SI, Pérol M, Dziadziuszko R, Rosell R, Zeaiter A, Mitry E, Golding S, Balas B, Noe J, Morcos PN, Mok T, ALEX Trial Investigators (2017) Alectinib versus Crizotinib in untreated $A L K$-positive nonsmall-cell lung cancer. N Engl J Med 377(9):829-838
2. Webb TR, Slavish J, George RE et al (2009) Anaplastic lymphoma kinase: role in cancer pathogenesis and small-molecule inhibitor development for therapy. Expert Rev Anticancer Ther 9(3):331356

3. Limited, Roche Products Pty (2017) Product information for AusPAR Alecensa Alectinic hydrochloride. Therapeutic Goods Administration

4. Camidge DR, Dziadziuszko R, Peters S, Mok T, Noe J, Nowicka M, Gadgeel SM, Cheema P, Pavlakis N, de Marinis F, Cho BC, Zhang L, Moro-Sibilot D, Liu T, Bordogna W, Balas B, Müller B, Shaw AT (2019) Updated efficacy and safety data and impact of the EML4-ALK fusion variant on the efficacy of alectinib in untreated ALK-positive advanced non-small cell lung cancer in the global phase III ALEX study. J Thorac Oncol 14(7):1233-1243

5. Yang JCH, Ou SHI, de Petris L, Gadgeel S, Gandhi L, Kim DW, Barlesi F, Govindan R, Dingemans AMC, Crino L, Lena H, Popat S, Ahn JS, Dansin E, Golding S, Bordogna W, Balas B, Morcos PN, Zeaiter A, Shaw AT (2017) Pooled systemic efficacy and safety data from the pivotal phase II studies (NP28673 and NP28761) of alectinib in ALK-positive non-small cell lung cancer. J Thorac Oncol 12(10):1552-1560

6. Wong P (2004) A basis of the acanthocytosis in inherited and acquired disorders. Med Hypotheses 62(6):966-969

7. de Franceschi L, Tomelleri C, Matte et al (2011) Erythrocyte membrane changes of chorea-acanthocytosis are the result of altered Lyn kinase activity. Blood 118(20):5652-5663

8. Al-Mahdili HA, Hooper AJ, Sullivan DR et al (2006) Case report a mild case of abetalipoproteinaemia in association with subclinical hypothyroidism. Ann Clin Biochem 43(Pt 6):516-519

9. Filippini A, Villa G, Corrocher R, de Franceschi L (2007) Acute hemolytic anemia with acanthocytosis associated with high-dose misoprostol for medical abortion. Ann Emerg Med 50(3):289-291

10. Morse E (1990) Mechanisms of hemolysis in liver disease. Ann Clin Lab Sci 20(3):169-174

11. Shinar E, Rachmilewitx EA (1990) Differences in the pathophysiology of hemolysis of $\alpha$ and $\beta$-thalassemic red blood cells. Ann N Y Acad Sci 612:118-126

Publisher's note Springer Nature remains neutral with regard to jurisdictional claims in published maps and institutional affiliations. 